\title{
Management Options in Patients with Trapped Temporal Horn: Case Report and Critical Review
}

\section{Joel Caballero-García*, Juvenal Huanca-Amaru, Carlos Aparicio-Garcia, Misael Lopez-Sanchez and Jhohana Linares Benavides}

National Institute of Oncology and Radiobiology, Cuba

*Corresponding author: Joel Caballero-Garcia, National Institute of Oncology and Radiobiology, 23 Street, Number 301, Apto C-12, Vedado, La Habana, PC: 10,400, Cuba, Tel: 053-226-881

\begin{abstract}
Background: Standard treatment for trapped temporal horn has not been established yet for this unusual condition, and a variety of surgical strategies have been reported.

Case description: A 58-year-old woman with a previous history of partial resection for a parietal glioblastoma in another center and trapped temporal horn is presented. A ventriculoperitoneal shunt was done with completely resolution of the temporal lobe entrapment.

Conclusions: Trapped temporal horn is a rare condition, and many different surgical approaches have been described. Ventriculoperitoneal shunting remains the standard treatment and has some particularly advantages in patients with malignant tumors. The ideal treatment should be selected after a case-by-case analysis.
\end{abstract}

\section{Keywords}

Trapped temporal horn, Obstructive hydrocephalus, Ventricular tumor

\section{Introduction}

Trapped temporal horn constitutes an special type of obstructive hydrocephalus and is caused by obstruction and/or adhesion related to various etiologies [1]. A proximal temporal horn blockage can cause dilatation of the distal part resulting in compression symptoms and lately in death relative to uncal and hippocampal herniation [2].

Standard treatment has not been established yet for this unusual condition, and a variety of surgical strategies have been reported [3-9].
Here we report a case successfully treated with ventriculoperitoneal shunt. The advantages and disadvantages of each techniques is discussed and a critical literature revision is performed.

\section{Case Description}

A 58-year-old woman presented to our institution with a previous history of partial resection for a parietal glioblastoma in another center after she presented with epilepsy. After that, she started with sensitive aphasia and disorientation. The postoperative Magnetic Resonance Image (MRI) showed a persistent mass with ring enhanced with splenium of corpus callosum invasion (posterior butterfly glioblastoma) and temporoparietal brain edema (Figure 1A). A left ventricular atrium invasion and an enlarged left temporal horn (trapped temporal horn) was observed with brainstem compression and imagenologic signs of uncal herniation (Figure 1B and Figure 1C).

The patient was immediately translated to the operation room for an urgent ventriculoperitoneal shunting procedure.

\section{Operative Procedure}

Under general anesthesia the patient was placed in a supine position with a roll placed below the left shoulder and the head turned 90 degrees withought rigid cranial fixation. Ceftriaxone $(1 \mathrm{~g})$ was used as antibiotic prophylaxis. A small vertical temporal incision $(2.5 \mathrm{~cm})$ was planned (Figure 2A) to make a small burr hole $3 \mathrm{~cm}$ anterior and superior to the external acoustic meatus

Citation: Caballero-García J, Aparicio-García C, López-Sánchez M, Benavides JL, Juanca-Amaru J (2020) Management Options in Patients with Trapped Temporal Horn: Case Report and Critical Review. Neurosurg Cases Rev 3:032. doi.org/10.23937/2643-4474/1710032

Accepted: April 16, 2020; Published: April 18, 2020

Copyright: (C) 2020 Caballero-García J, et al. This is an open-access article distributed under the terms of the Creative Commons Attribution License, which permits unrestricted use, distribution, and reproduction in any medium, provided the original author and source are credited. 


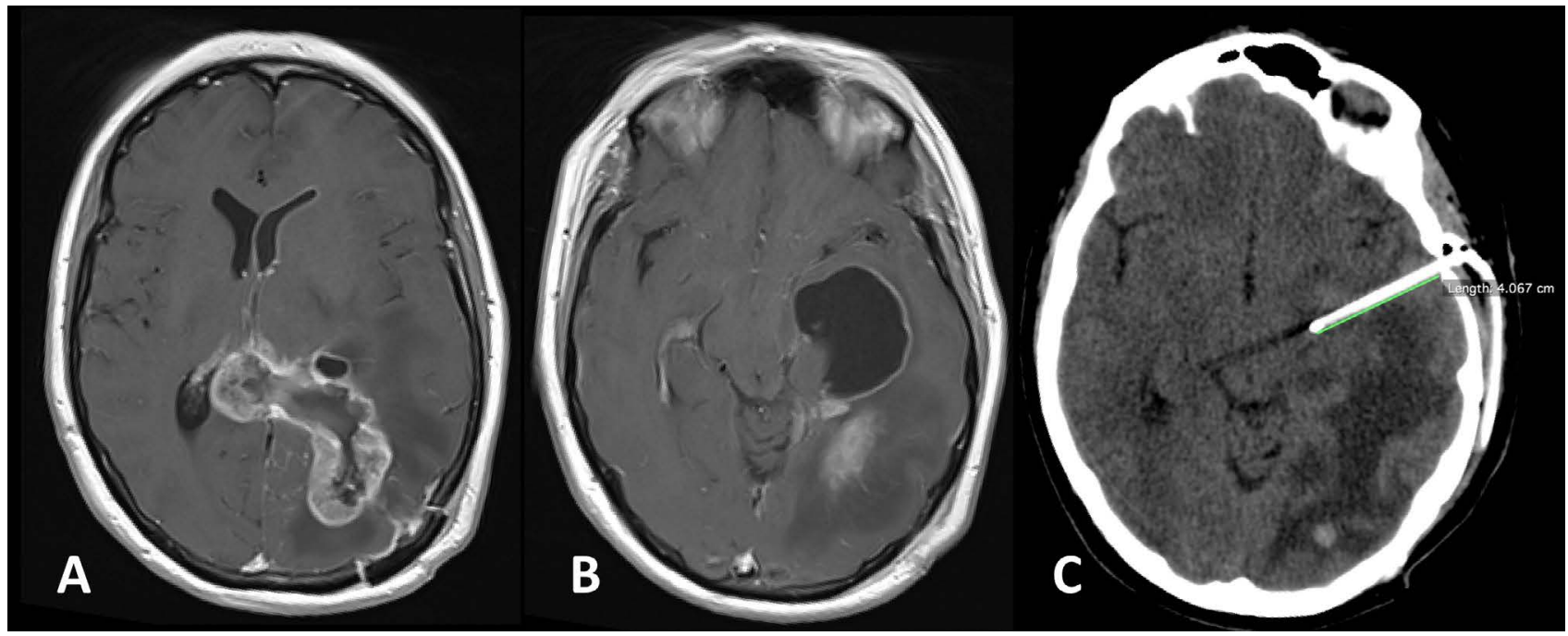

Figure 1: Preoperative and postoperative imaging. A) A T1-weighted MRI enhancing mass in the left parietal lobe and the splenium, which occupying the left ventricular atrium; B) A preoperative T1-weighted MRI revealed enlargement of the temporal horn of the left lateral ventricle with brainstem compression; C) A 24 hours postoperative Computed Tomography (CT) scan demonstrated a completely resolution of the temporal lobe entrapment.
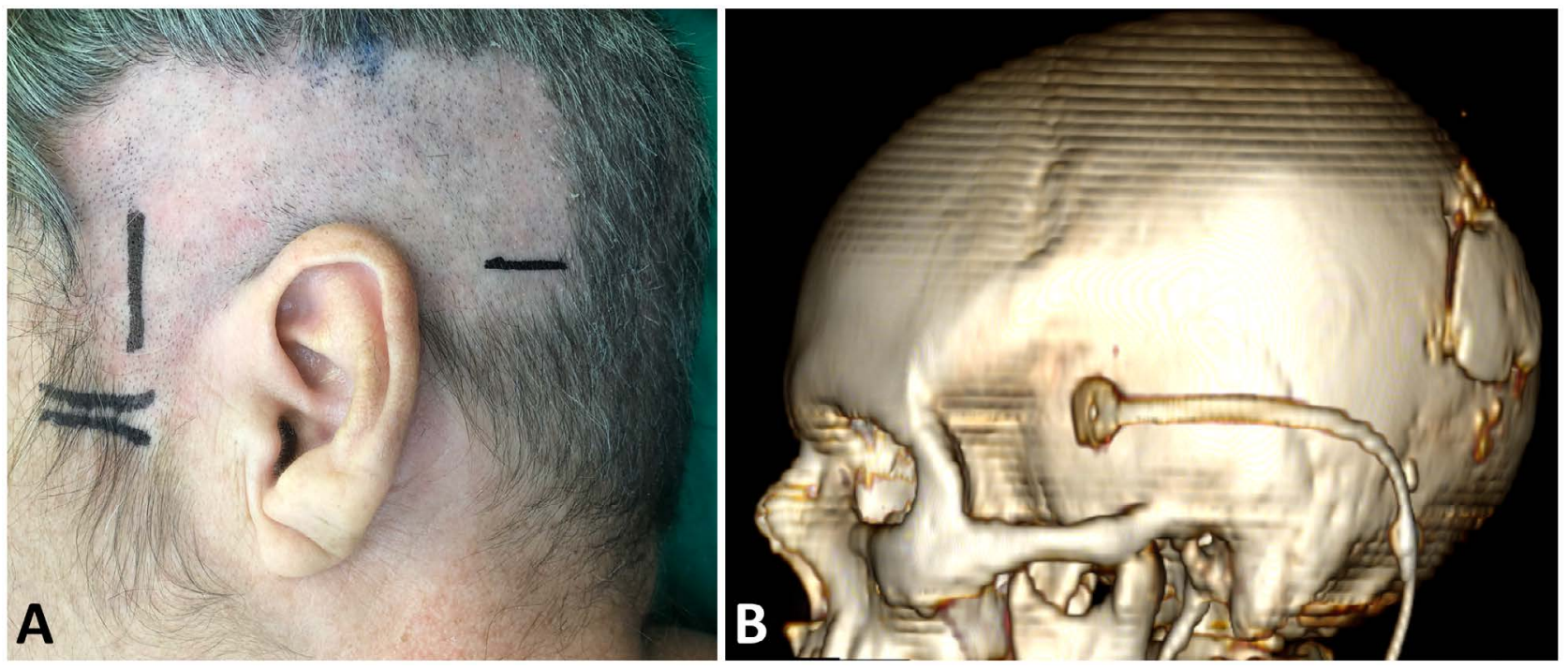

Figure 2: A) Preoperative picture exposed the surgical incisions; B) A 3D reconstruction of a CT scan revealed the position of the burr hole and direction of the distal ventriculoperitoneal catheter.

(Figure 2B). The abdominal incision was performed in the left side until the peritoneum was reached. A second small cranial incision was performed in a horizontal direction situated above the base of mastoid process to facilitated tunelization of distal catheter (Figure 2A). After coagulation and dural opening the ventricular catheter was inserted perpendicularly to the external table and $4 \mathrm{~cm}$ of deeper. The temporal horn was reached and a high pressure of cerebrospinal fluid was observed. An occlusion of the ventricular catheter was performed to prevent rapid decompression. A cerebrospinal fluid sample was taken and the ventricular and distal catheter were communicated. The valve was anchored to the periosteum to prevent its migration. We used a ultralow pressure valve. Finally, the distal part of the shunt was inserted inside the intraperitoneal space under direct visualization. All surgical incisions was closed in a rou- tinely way and the patient was extubated in the operation room.

\section{Postoperative Course}

In the early postoperative period the somnolence disappeared and 48 hours after the aphasia improved. The patient remains withought headache or other symptoms. The CT scans revealed a completely resolution of the temporal horn dilatation.

Once the trapped temporal horn resolved, radiotherapy and concurrent treatment with chemotherapy (Temozolomide) and monoclonal antibody treatment (Nimotuzumab) were initiated.

\section{Discussion}

Partial enlargement of a lateral ventricle represents 
an special form of an obstructive hydrocephalus which includes the ventricular body obstruction that cause dilatation of temporal horn, occipital horn and trigone. Trigone obstruction cause dilatation of temporal and occipital horns, and temporal obstruction (also called sphenoidal obstruction) cause trapped temporal horn [10].

Trapped temporal horn was first described by Cairns and Daniel in 1947 [11] and could be seen in different conditions such as penetrating trauma, meningitis, ventriculitis, intraventricular cysticercosis, hydatic cysts, neurosarcoidosis, intraventricular arachnoid cysts, and postresection intra or paraventricular tumors (around or in ventricular trigone) like malignant glioma in the splenium, or trigone meningiomas $[1,3,12]$. In our case, persistent mass effect of the remain tumor caused obstruction of the left lateral ventricle at the level of the atrium ant temporal horn. In such cases the choroid plexus of the temporal horn unceasing to produce cerebrospinal fluid and the blockage of its outflow leads a progressive dilation of the temporal horn.

Clinical manifestations are secondary to mass effect of the temporal horn dilated and includes manifestations called "trapped temporal horn syndrome" like homonymous hemianopia due the compression of Meyer's loop; hemiparesis due the compression of the internal capsule; memory disturbances due hippocampal compression; sensitive aphasia in dominant hemispheres and symptoms related to increased intracranial pressure like headache, gait disturbance and confusion. Due the risk of uncal herniation a rapid clinical deterioration with decreased level of consciousness can be observed [10]. Consequently, trapped temporal horn represents a neurosurgical urgency [2]. In our patient, a rapid improvement of the level of consciousness after the cerebrospinal diversion makes the sensitive aphasia more evident at the beginning of postoperative period. Such previous history of sensitive aphasia was related to the left parietal location of the tumor and surrounded edema, however, this symptom improve 48 hours after the cerebrospinal diversion, soon we think that was secondary to the trapped temporal horn more than to the tumor itself.

In patients with any form of obstructive hydrocephalus a cerebrospinal fluid conversion should be indicated due the high risk of mortality and to improve the life quality, especially in oncological patients. However, some authors had advocated closely observation withought treatment in asymptomatic patients [1].

Surgical options include reestablishing connection to the cerebrospinal fluid pathway or drainage of the trapped temporal horn via a shunt. Reconnection to the cerebrospinal fluid pathway can be accomplished by fenestration or dilation of the membranous trigone area, the resection of the compressive lesion to reestablish connection to the lateral ventricle or the connection to the subarachnoid space by temporopolar tip amputation [3].

The ventriculoperitoneal shunt has conventionally been the preferred procedure for the trapped temporal horn. However, there are different surgical techniques for ventricular catheter insertion. In 2015, Bohl, et al. [2] compared 3 different trajectories for temporal horn catheter insertion: perpendicular approach, medial approach and lateral approach. They concluded that the perpendicular approach (which was used in this case) is likely the easiest, safest, and most reliable for temporal horn catheterization.

There are recent reports of neuro endoscopic procedures as an alternative methods in selected cases, which can diminishing the risks related to shunt insertion such as infections, obstruction, dependency and over-drainage complications $[4,5,9]$. In such cases, the responses is dictated by a pression gradient between the ventricle and cistern. However, there will founded this procedure may still end up with stenosis or closure of the stoma which is observed in $7 \%$ to $75 \%$ of the patients [7]. In order to avoid that, other authors had also reported a stein placement, like in aqueduct stenting for isolated fourth ventricle [6]. However, this procedure carries inherent limitations. For example, if the tissue gets in through side holes and occludes the stent the trapped temporal horn recurs. Another problem is the possibility of stent migration. To prevent that, Hanna, et al. [6] suggested to connecting it to an Omaya reservoir anchored to the periosteum. Instead, hardware placement increases the risk of infection. On the other hand, the stent can cause damage to neurovascular structures like the cerebral peduncles, cranial nerves, posterior communicant artery or perforating arteries [6]. Neuronavigation constitutes a helpful resource to avoid those complications but we should take in count the anatomical distortion after the ventriculostomy which decreases the stereotactic accuracy. Moreover, this procedure needs favorable anatomical features because the dilation of the temporal horn widens the window between the anterior choroidal artery and optic tract superiorly, and the posterior communicating artery and third cranial nerve inferiorly, making the procedure feasible. Only when that window is wide enough and the mesial wall thin enough should the procedure be attempted. On the other hand, the prepontine cistern should be patent $[1,6]$. Other authors have described a frontal to temporal horn shunting [8].

In patients with malignant tumor the therapeutic approach must ensure a safe and durable cerebrospinal conversion in order to avoid reinterventions which could interrupt or delay the oncological treatment. We consider that ventriculoperitoneal shunting has some advantages in such cases compared with endoscopic 
Table 1: Advantages and disadvantages of the definitive surgical options for a entrapped temporal horn.

\begin{tabular}{|c|c|c|c|}
\hline Surgical option & Advantages & Disadvantages & Major indications \\
\hline $\begin{array}{l}\text { Ventriculoperitoneal } \\
\text { shunting }\end{array}$ & $\begin{array}{l}\text { Well demonstrated results } \\
\text { Intracranial pressure relieve } \\
\text { High effectiveness }\end{array}$ & $\begin{array}{l}\text { Shunt dependency } \\
\text { Shunt relative complications Possibility of } \\
\text { abdominal spread in malignant tumors }\end{array}$ & Suitable for all cases \\
\hline $\begin{array}{l}\text { Frontal to temporal } \\
\text { shunting }\end{array}$ & $\begin{array}{l}\text { No risk of malignant cells spread } \\
\text { outside the head }\end{array}$ & $\begin{array}{l}\text { Limited in displaced or collapsed frontal } \\
\text { horn } \\
\text { Tumor growing can displaced the shunt }\end{array}$ & $\begin{array}{l}\text { Favorable frontal } \\
\text { horn anatomy }\end{array}$ \\
\hline $\begin{array}{l}\text { Endoscopic } \\
\text { ventriculocisternostomy }\end{array}$ & $\begin{array}{l}\text { No risk of malignant cells spread } \\
\text { outside the head } \\
\text { Can be used in cases of infection }\end{array}$ & $\begin{array}{l}\text { Possibility of spontaneous } \\
\text { ventriculostomy closure or after } \\
\text { radiotherapy } \\
\text { Neuronavigation dependent }\end{array}$ & $\begin{array}{l}\text { Favorable anatomy } \\
\text { Biopsy necessity }\end{array}$ \\
\hline $\begin{array}{l}\text { Endoscopic } \\
\text { ventriculocisternostomy } \\
\text { with a stein placement }\end{array}$ & $\begin{array}{l}\text { No risk of malignant cells spread } \\
\text { outside the head } \\
\text { Less risk of disfunction }\end{array}$ & $\begin{array}{l}\text { Theorically more risk of infection than in } \\
\text { the endoscopic ventriculostomy } \\
\text { Tumor growing can displaced the shunt } \\
\text { Risk of migration } \\
\text { Neuronavigation dependent }\end{array}$ & $\begin{array}{l}\text { Favorable anatomy } \\
\text { Biopsy necessity }\end{array}$ \\
\hline Temporal tip removal & $\begin{array}{l}\text { No risk of malignant cells spread } \\
\text { outside the head }\end{array}$ & More invasive procedure & $\begin{array}{l}\text { Alternative to } \\
\text { endoscopy in cases } \\
\text { that requires a biopsy }\end{array}$ \\
\hline Etiologic treatment & $\begin{array}{l}\text { Restores the cerebrospinal fluid } \\
\text { physiology }\end{array}$ & Risk of recurrence & $\begin{array}{l}\text { Only for benign } \\
\text { tumors which can be } \\
\text { completely resected }\end{array}$ \\
\hline
\end{tabular}

procedures with or withought stent. First of all, this is a well-proven method to control hydrocephalus, and some complications are relative to the quality of the system employed and not to the method itself. Second, this patients usually develop high intracranial pressure due the tumor, the brain edema and the hydrocephalus, so ventriculoperitoneal shunting can contribute to release the pressure opposite to other methods that covers the cerebrospinal fluid to other places inside the head. Moreover, employment of a stein method include a similar risk of infection or obstruction than ventriculoperitoneal shunting. Last but not least, we should take in count that this patients can developed a communicative hydrocephalus due infections, tumor cells, surgical bleeding and also radiotherapy, and other methods than ventriculoperitoneal shunting are in such cases ineffective making a versatile procedure the ideal method.

One disadvantage of ventriculoperitoneal shunting could be the possibility of abdominal spread by malignant tumor cells, however, the relative short life expecting in these patients makes symptoms due abdominal spread improbable. In the Table 1, the advantages and disadvantages of each methods described is summarized.

However, alternatives like endoscopic ventriculostomy or stents could be useful in similar cases with contraindication of ventriculoperitoneal shunting like paralytic ilium, or insufficient peritoneum for different conditions. Consequently, the method employed should be determined after a case-by-case basis.

\section{Conclusions}

Trapped temporal horn is a rare condition, and many different surgical approaches have been described. Ventriculoperitoneal shunting remains the standard treatment and has some particularly advantages in patients with malignant tumors. The ideal treatment should be selected after a case-by-case analysis.

\section{References}

1. Paredes I, Orduna J, Fustero D, Alvarez Salgado JA, Belinchon de Diego JM, et al. (2017) Endoscopic temporal ventriculocisternostomy for the management of temporal hornentrapment: Report of 4 cases. J Neurosurg 126: 290-303.

2. Bohl MA, Almefty KK, Nakajii P (2015) Defining a standardized approach for the bedside insertion of temporal horn external ventricular drains: Procedure Development and Case Series. Neurosurgery 1-9.

3. Berhouma M, Abderrazek K, Krichen W, Jemel H (2009) Apropos of anunusual and menacing presentation of neurosarcoidosis: The space-occupying trapped temporal horn. Clin Neurol Neurosurg 111: 196-199.

4. Chen CC, Kasper EM, Zinn PO, Warnke PC (2013) Management of entrapped temporal hornby temporal horn to prepontinecisternshunting. World Neurosurg 79: 404.e7404.e10.

5. Parrent AG, EKrahenbuhl AK, Baldauf J, Gaab MR, Schroeder HW (2013) Endoscopic temporal ventriculocisternostomy: Anoption for the treatment of trapped temporal horns. J Neurosurg Pediatr 11: 568-574.

6. Hana T, Tanaka S, Shin M, Mukasa A, Kugasawa K, et al. (2015) Neuroendoscopic ventriculocisternostomy with stent placement for trapped temporal horn after the resection of glioblastoma. World Neurosurg 84: 2078. 
7. Gliemroth J, Kaasbeck E, Kehler U (2014) Ventriculocisternostomy versus ventriculoperitoneal shunt in the treatment of hydrocephalus: A retrospective, long-term observational study. Clin Neurol Neurosurg 122: 92-96.

8. Hervey-Jumper SL, Ziewacz JE, Heth JA, Sullivan SE (2010) Frontal-to-temporal horn shunt as treatment for temporal horn entrapment. J Neurosurg 112: 410-413.

9. Kraahenbuuhl AK, Baldauf J, Gaab MR, Schroeder HW (2013) Endoscopic temporal ventriculocisternostomy: An option for the treatment of trapped temporal horns. J Neurosurg Pediatr 11: 568-574.
10. Watanabe T, Katayama $Y$ (1999) Evaluation by magnetic resonance imaging of the entrapped temporal horn syndrome. J Neurol Neurosurg Psychiatry 66: 113.

11. Cairns H, Daniel P (1947) Localized hydrocephalus following penetrating wounds of the ventricle. Br J Surg 55: 187197.

12. Wang $Y$, Lin Z, Zhao M, Hu M, Zhang H, et al. (2016) The incidence and risk factors of postoperative entrapped temporal horn in trigone meningiomas. World Neurosurg 90: 511-517. 